\title{
Notes for Contributors
}

The World's Poultry Science Journal publishes: review articles on all aspects of poultry science, reports on the development of poultry production from around the world, reports from constituent scientific working groups, book reviews, Association and Branch news, together with a listing of forthcoming events. Summaries of the review articles are published in French, German, Russian and Spanish. The journal does not publish the results of original research unless these form a minor part of an article that mainly reviews published work, or where they are contained in reports given at branch meetings or arise from the activities of Federation Working Groups. Among the characteristics considered important in a review paper are that it should be comprehensive within the area defined by its title, the structure should be logical and the citations should be subjected to critical appraisal - which should extend to the methodology and statistical significance of results. In preparing a review, sound deductive and constructive processes should be used to produce valid, useful and clearly presented conclusions. The appropriate use of figures, tables, formulae and illustrations is encouraged. The object must always be to produce a worthwhile addition to the body of available literature.

\section{Typescripts}

Typescripts should be in English and should be sent in duplicate, to the Editor, World's Poultry Science Journal, Dr J. M. McNab, Roslin Institute (Edinburgh), Roslin, Midlothian EH25 9PS, UK. Contributions, which will be subject to scrutiny by independent referees and editorial revision, should normally not be longer than the equivalent of 8-10 pages of the journal (or approximately 6000 words) including tables, illustrations and references. Longer reviews are accepted from time to time, but it is advisable for authors to contact the Editor before submission. Papers should be typewritten on one side of the paper only and the typing should be double-spaced between lines with ample margins on each side of the sheet. The automatic numbering of lines in the margin is a great advantage. Pages should be assembled in the order: title; name and postal address(es) of author(s); where applicable, name and address of institution where the work was done; summary of between 100 and 300 words; keywords (up to 8); text of paper; references; tables; figures; figure legends (on separate page); abbreviated title (for use as a running headline). The pages of the paper itself should be numbered in the upper right-hand corner and should only be fastened by means of a paperclip. To enable summaries to be translated into French, German, Russian and Spanish, contributions should be accompanied by an additional copy of the summary (in English) of 100-300 words, typed on a separate sheet of paper.

\section{References}

References to previous work should be cited in the text with the author's name and the year of publication in parentheses, e.g. 'Brown (1957) showed that . . ' At the end of the paper, the references should be listed in alphabetical order of the surnames of the first author with all authors included, e.g. 'BROWN, A.B., SMITH, C.D. and JACK, E.F. . . ' . The titles of journals should be given in full and should include the first and last page numbers of the papers concerned. 


\section{Tables, line drawings and photographs}

Tables and line drawings should be typed or drawn on separate sheets and their approximate location in the text indicated in pencil; they should rot be enclosed by lines. Tables should be typed with adequate spacing, keeping column headings as brief as possible, and they should include a self-explanatory legend. Line drawings should be clearly drawn in black on white paper. Computer produced figures must be from high quality printers, e.g. laser or bubble jet. Photographs of line drawings may be submitted. Black and white photographs (half-tones) submitted, preferably not smaller than $110 \mathrm{~mm} \times 150 \mathrm{~mm}$, should be glossy prints of good contrast and, where necessary, should carry a scale mark of magnification. Lettering may be placed on the print or on a tracing paper overlay, which should be fixed securely to the print along one edge only. Legends for line drawings and half-tones should be typed on a separate sheet. The author's name and figure number should be written on the back of each line drawing or photograph.

\section{Footnotes}

Footnotes should be avoided wherever possible. Where essential they should be indicated by asterisks $\left({ }^{*}\right)$, daggers $(t)$ and double daggers $(\ddagger)$ in that order. In the manuscript, a footnote should be placed at the bottom of the page on which it is referred to and separated from the main text by a horizontal line above the footnote. Footnotes to tables should be placed underneath the table to which they refer.

\section{Proofs}

Page proofs will be supplied to the senior author, whose responsibility it is to liaise with co-authors in checking the proofs, but only errors in typesetting may be corrected at this stage. Additional matter or extensive alterations can be accepted only at the discretion of the Editor, and, if they are accepted, a charge may be made. Consequently, the author(s) should ensure that the paper is submitted in its final form. Proofs must be corrected and returned within 10 days of receipt.

\section{Offprints}

A total of 50 offprints will be sent free of charge to the senior author of each paper published. Additional offprints can be ordered at the prices shown on the offprint order form which will be sent with the proofs.

\section{Submission of papers}

Typescripts and matters relating to the content of the journal should be addressed to the Editor, Dr J. M. McNab, Roslin Institute (Edinburgh), Roslin, Midlothian EH25 9PS, UK.

\section{Back numbers}

Requests for back numbers up to the completion of Volume 44 (1988) should be addressed to the Editor, as above. For back numbers from Volume 45 (1989) onwards, please make application to the Secretary of the World's Poultry Science Association, Dr Ir Piet C.M. Simons, Centre for Applied Poultry Research, "Het Spelderholt", Postbus 31, 7360 AA Beekbergen, The Netherlands (Tel. + 3155506 65 34, Fax: +3155 5064858 ). 


\section{$1^{\text {th }}$ European Poultry Conference \\ September 6 - 10, 2002 \\ Bremen, Germany}

\section{A WORD FROM THE PRESIDENT}

Dear Colleagues and Friends of Poultry,

On behalf of the German Branch of WPSA, I cordially invite you to the 11th European Poultry Conference in Bremen in the North of Germany. Bremen is conveniently located and easy to reach from all European countries.

The open-minded and friendly Hanseatic city Bremen offers a modern congress centre, recently built near the main railroad station and ideally suited for conferences.

Near Bremen is the Weser-Ems region, well known for its concentration of poultry meat and egg production. The conference program will offer several opportunities to participate in informative field excursions.

The scientific program of the $11^{\text {th }}$ European Poultry Conference will update information in all fields of poultry science and production. Special emphasis will be to issues relating to consumer acceptance of products and production systems, including changing breeding goals and nutrition and disease control in response to new standards for animal welfare and ecological production.

We are especially looking forward to the active participation of our colleagues from Eastern European countries and to exchange information relevant to their research projects and production environments.

Bremen has much to offer for an interesting and diversified cultural by-programme. Join us to help celebratethe 50th anniversary of the German Branch of WPSA.

We look forward to welcome you in Bremen in September 2002.

\section{Johannes Petersen}

President, German Branch of WPSA

Please send your Notice of Intend to:

11th European Poultry Conference, 2002

Congress Partner

$\mathrm{T}:+49-421 / 303130$

Birkenstr 17

F: $+49-421 / 303133$

28195 Bremen

email: CongressPartner.Bremen@t-online.de

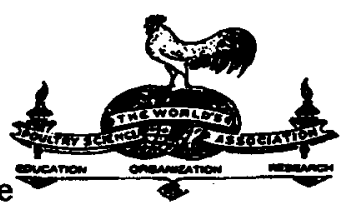

